\title{
Spatial Equity and High Speed Trains: The Example of France
}

\author{
Dominique Bouf ${ }^{1}$, Christian Desmaris ${ }^{2, *}$ \\ ${ }^{1}$ Laboratory Development Economy Transport (LAET), National Center for Scientific Research (CNRS), France \\ ${ }^{2}$ Institute of Political Studies (IEP), University of Lyon, France
}

Received April 12, 2020; Revised July 20, 2020; Accepted August 10, 2020

\section{Cite This Paper in the following Citation Styles}

(a): [1] Dominique Bouf, Christian Desmaris , "Spatial Equity and High Speed Trains: The Example of France," Sociology and Anthropology, Vol. 8, No. 5, pp. 143 - 158, 2020. DOI: 10.13189/sa.2020.080501.

(b): Dominique Bouf, Christian Desmaris (2020). Spatial Equity and High Speed Trains: The Example of France. Sociology and Anthropology, 8(5), 143 - 158. DOI: 10.13189/sa.2020.080501.

Copyright $\bigcirc 2020$ by authors, all rights reserved. Authors agree that this article remains permanently open access under the terms of the Creative Commons Attribution License 4.0 International License

\section{Preliminary Note}

What has changed since May 2015?

We can think of three major changes since the presentation of the paper.

1) The French HSR network has been extended and larger urban areas are linked to Paris by High Speed Train. It is possible that the difference observed between cities benefiting from HSR and the others may be temporary. One factor may have played a role, namely that the most dynamic urban areas were connected to Paris first. Another study would be useful to address the issue of growth of the regions served by HSR, with a "before" and "after" comparison, taking into account the date on which HSR services began. Perhaps this new study could benefit from an international perspective. Regarding French HSR, it is necessary to wait for the long-term effects of the new line serving Bordeaux, which is now 2 hours away from Paris. But some scholars consider that the Bordeaux urban area has a specific dynamic that may not be linked with proximity to Paris.

2) SNCF has introduced a number of low-cost HSTs (called Ouigo) and been developing these services. This might make it easier to find an affordable journey to Paris, if the traveller is free to choose their time of departure. This is probably a strategic move to propose low prices and thus attracting new ridership. Even if this is not the objective, HST can increase the fairness of the whole system. A new study would be very useful, once the supply of low-cost trains can be considered stable and large enough to affect the fairness of the system.

3) When we wrote this presentation, studies on the equity of rail systems were quite rare. This is no longer the case for urban or interurban rail networks. A number of papers have been published, in particular on the Chinese Rail system. A far from exhaustive list includes the following: Appleyard B.S. 2019; Carleton P.R. and Porter J.D., 2018; Guye Yuje (2020 in Press); Kelobonye and al., 2019; Shang Pan and al., 2018; Song Yenna and al., 2018. 


\begin{abstract}
Although transport improvements are growth enhancing, they are probably unfair. There is no reason to suppose that High Speed Rail (HSR) is an exception. Given the context, the question of the equity of HSTs has once more taken centre stage. This paper aims to study HSR in France, in relation to spatial equity. In addition, we shall attempt to evaluate the different components of the railway system, which include infrastructure funding and pricing. We begin by examining some of the various concepts enclosed in the polysemic word "equity". Increased accessibility was one of the reasons for the development of HSR. We estimate a simple model to measure the possible effect of HSR on French regions. We found a positive effect on GDP per capita and demographic growth for regions with HSR, except for the Paris region. Thus, HSR could be considered unfair. In addition to this, the pricing system implemented by the operator, based on yield management and intermodal competition, produces a peculiar and singularly unfair pricing structure. Concerning the funding of HSL, the impacts on equity depend on the line in question. Our contribution addresses the question of the spatial equity of HSR, left aside at that time. We shall apply the concepts identified by Hay in order to analyse the French case. This approach might be helpful for China, a country with large income disparities and a clear need for an environmentally friendly inter-city transport policy, but also for some European HSR networks or East Asian countries with a capital city where a large proportion of the population is concentrated.
\end{abstract}

Keywords High-speed Trains, Spatial Equity, Regional Development, French Regions, Pricing, Funding

\section{Introduction}

Although transport improvements are growth enhancing, they are probably unfair. This is evidenced by a number of effects. Transport improvements often result in extraordinary privileges for some places, such as airports, stations, and ports. They can, therefore, be considered unfair from the point of view of the places which do not receive these privileges (users and non-users in the terms employed by Vickerman, 1997). Conversely, transport improvements almost always have some negative impacts: pollution, noise, severance effects and so on. It follows that the "winners" and the "losers" do not share the same location. This raises concerns about spatial fairness. There is no reason to suppose that High Speed Trains (HSTs) should be an exception.

Fairness, justice and equity were the subjects of many debates in the 90s. Given the particular context of High Speed Trains, the question of their equity has again returned to the centre stage. There are several reasons for this. First, enough time has now elapsed since the inception of the first High Speed Lines (HSLs) in Japan and France, so an appraisal of the spatial effects of HSLs is now possible (Albalate and Bel, 2012). Second, one very large country (China) has been building an impressive network of HSLs. Last, the US (Levinson, 2012) and UK, until now reluctant to invest in HSLs, are now seriously considering building networks. Equity matters are the subject of numerous debates in the UK (Preston, 2012) and spatial justice has long been at the core of Chinese policy. In many European countries that already have high-speed networks, the next HSLs are hotly debated (Spain, France, Italy, Sweden...). The commercially viable links have already been built and the justification for the future lines depends to a greater or lesser degree on questionable environmental considerations.

In this article, we propose to contribute to this debate between investment in transport and equity, by looking at how high-speed trains in France have affected spatial equity. We will choose a broad approach, encompassing an analysis of accessibility gains on economic development at the regional level, the pricing offered to travellers depending on their location and destination, and finally a review of the financing conditions for HSL. Regarding the first aspect, we propose simple modelling of the impact of TGV on regional development, understood in terms of GDP (Gross Domestic Product) and population. With the latter two aspects, we are at the heart of the dilemma facing the French national railway operator, SNCF, in turn, considered as a public service and a private company ${ }^{1}$.

Thus, our article will be presented in four parts. As equity is a polysemic word, in the first part of the paper, we will present the different concepts that will be used in the remainder of the paper, based on Hay (1995). By their very nature HSL investments might be considered as inequitable, but to back up this view, we have to quantify the effects of the accessibility gains. If the accessibility gains have no impact, the HST cannot be deemed inequitable. The second part of the paper is therefore devoted to the consequences of the increased accessibility resulting from HSTs. But accessibility has a cost and a price. Thus, in the third part, we consider the impact of the HST pricing system on spatial equity. In part four, we analyse the fairness of funding procedures.

\section{Expectations Regarding Equity or Fairness in Transport}

Equity is frequently considered with reference to the seminal work of Rawls (1971). But Rawlsian concepts

\footnotetext{
1 This paragraph has been added to the 2020 version.
} 
cannot easily be applied to spatial analysis. Hay (1995) defines eight concepts of Equity Fairness Justice (EFJ) with the aim of carrying out spatial studies.

The first is "Procedural fairness". This concept consists of a uniform application of rules over time and space. The difficulty in applying the concept of procedural fairness to HSTs is that the rules are fairly flexible, depending mainly on pricing and financing. The same rule does not apply everywhere. Methods of financing have evolved considerably and the pricing of high-speed trains is in some respects singular. We, therefore, consider that procedural fairness is absent if a rule does not apply everywhere with a reasonable degree of spatial uniformity.

Fulfilment of legitimate expectations. In relation to the definitions put forward by Hay (1995). We have qualified the term expectations by adding the adjective "legitimate". When one looks at HST, one notes some very optimistic expectations. High speed is sometimes seen as a magic wand. We have to admit that this concept might be confusing as it could prove difficult to determine the extent to which an expectation is legitimate.

Formal equality is a simple concept: people in the same situation receive similar benefits or suffer similar inconveniences. This notion is close to that of horizontal equity or commutative justice in the sense put forward by Aristotle. Obviously, depending on their location, citizens benefit to a greater or lesser degree from an HST. Formal equality is linked to the possible balance between poor accessibility and potential compensation and conversely between better accessibility and the price paid for it. This concept is linked to the pricing system and the funding of HST.

Substantive equality takes the argument one step further. It refers to equality of outcomes (net aggregate benefits minus net burdens). Applied to HST, this aspect expresses, in particular, the balance between what passengers pay and the benefit of their journey. Once again, the funding of HSL needs to be taken into consideration.

Equality of choices. By its very nature, new infrastructure alters the amount of choice available to customers. In this paper, we take the view that HSTs are unfair according to this concept if a significant number of customers have less choice after the HSL has been set up.

In accordance with merit (meritocracy). Some people might benefit fortuitously from any transport improvement, possibly to the detriment of others. This may involve either firms or private individuals. Such situations are frequently found in the transport sector.

Rights. This concept may not be very relevant to our study. HSTs do not really breach the fundamental rights of citizens. Funding could perhaps be considered in this context, but if we take the view that we live in democratic societies, the decisions of central and local government should be deemed not to breach the rights of the citizens.

Corresponding to needs "Certain needs are so basic that failure to meet them is an injustice". We take the view that
HSTs have no bearing on basic needs. They do not meet basic needs and they do not prevent any basic needs from being met. So, in the remainder of the paper, we have not considered this aspect of Equity.

\section{Accessibility and Regional Impacts of HSR in France: Polarization and Spread}

Solving the overcrowding of some rail links was one of the reasons HSLs were developed. But increasing accessibility was also a goal. To a large degree, both objectives have been achieved in France, for the regions that are served. These accessibility gains mainly concern the travel time between Paris and some more or less remote regions.

Regarding the regional impact, there has been much conjecture but very few ex-post analyses, especially concerning long-term effects. The literature on the ex-post assessment of high-speed lines is limited to case studies (UIC, 2011). The consensus is that building an HST does not automatically boost the economies of the cities served (Albalate and Bel, 2012; Givoni, 2006). The effects of HSTs can be observed at various levels from regions to station neighbourhoods and recent research tends to favour multi-level analysis (Garmendia et al. 2012; Urena et al., 2009). So far, most research has dealt exclusively with cities, some Japanese studies excepted (Sands, 1993). In spite of a host of case studies, it is still unclear whether HSTs have a true impact on firms' location decisions, job creation, and ultimately regional productivity. In particular, it is not clear whether the impacts of HSTs are limited to major cities or if they spread out to cover a larger zone. However, Chen and Hall (2012) found that both the Lille region (Nord Pas de Calais) and the Manchester region have benefited from their HSTs, although this does not apply to every part of the regions in question.

In provincial regions, the results of these accessibility gains remain highly questionable. Indeed, if the effects of HST on major links were discernible, intra-regional accessibility may even have diminished. Moreover, there is a kind of "tunnel effect" (Plassard, 1991) which consists of poor accessibility for cities located near the HSL with poor access to the main cities. Moreover, some cities have lost their links to Paris (FNAUT, 2011).

\subsection{The Hypotheses of the Model}

It is interesting to address the effect of the HSTs at the regional level (France is divided into 22 regions) for the following reasons:

1) The choice of this geographical level enables us to have economic and demographic data that are not available at a lower level; 
2) The spatial spillover effects between the statistical units are limited;

3) Rail transport between the cities in a given region are organised by the regional assembly;

4) Some regions have HSTs and some do not, which makes comparisons between the two possible.

We shall begin with a brief description of the French "Régions". Spatially, these are frequently organised around a regional capital. Their surface area is comparable to that of a small European country, somewhere between Luxembourg and Switzerland. Apart from the Paris Region and Corsica, their populations range between 1.8 million and 6.2 million. They are not homogenous as they have both large cities and rural areas. But since the inception of
French HSLs, the bulk of the population travelling inter-regionally by rail live in the major urban areas (Bonnafous, 1987).

The main research hypothesis is thus that regional transport and the spread of HSTs in a region improves accessibility throughout that region. To test this hypothesis, we examine whether the benefit of greater accessibility is discernible with macroscopic data such as GDP or population. This has to be done in the long term, because a small growth differential can lead to a large effect over 20 years. We thus have two hypotheses:

1) The effects of HST can be observed at the regional level;

2) Long-term effects are observable (over several decades).

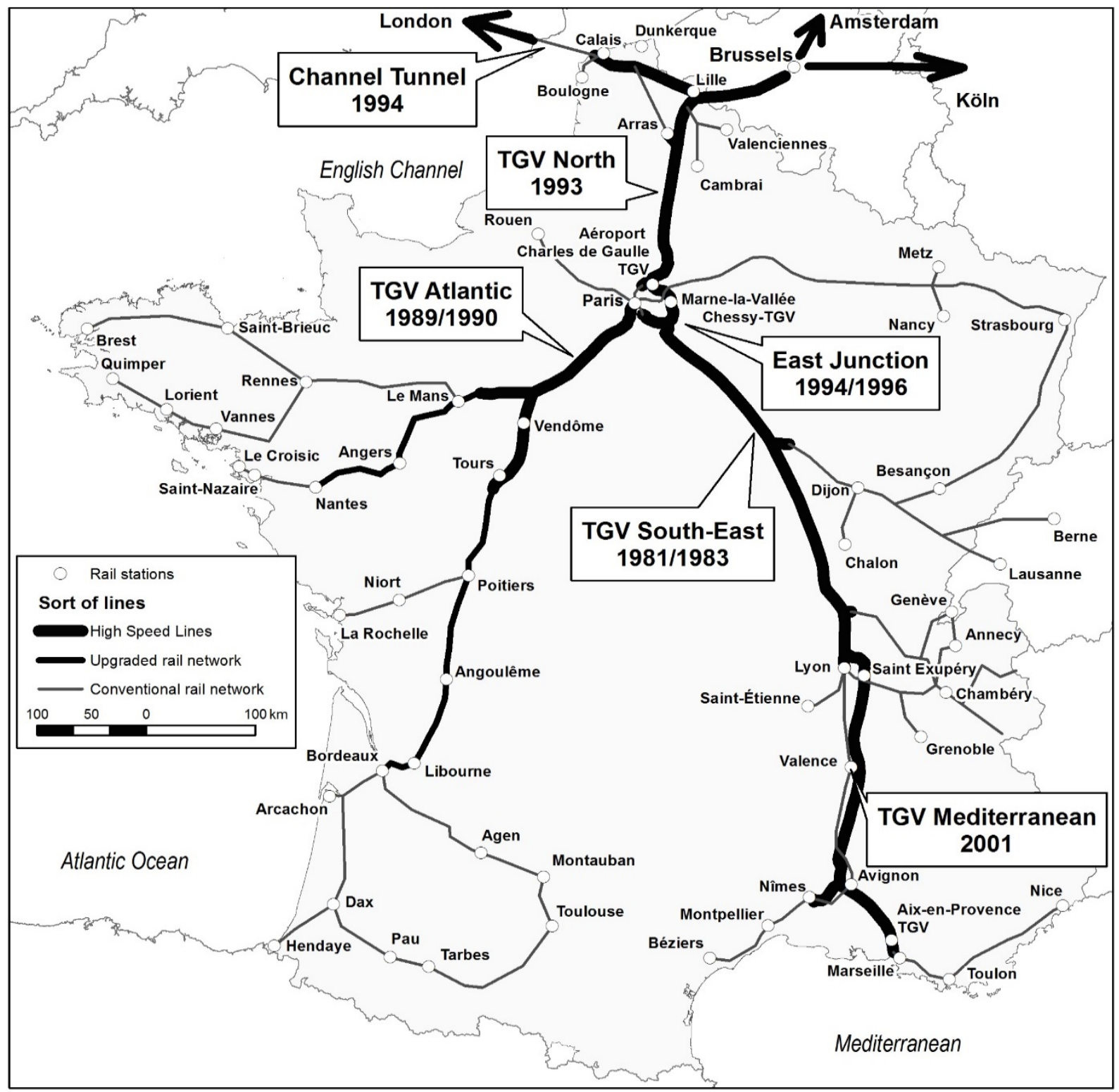

Source: Adapted by I. Baraklianos from Vickerman 1997. This is a selection of the relevant lines (the total length of the French network is actually $30,000 \mathrm{~km}$, around half of which is not used).

Figure 1. High speed lines and rail network in France in December 2007. 
The data provided by INSEE (French statistical bureau) consist of GDP and population for the 22 (metropolitan) French Régions in the period 1990-2011.

TGV is the French acronym for HST. In the paper, we will use TGV or HST arbitrarily.

The French TGVs were brought into operation as follows (Fig. 1.):

- 1981 and 1983: South-East TGV (Paris-Lyon)

- 1989-1990: TGV Atlantic to Brittany and Aquitaine

- 1993: TGV North, to Lille and later London, Brussels and Amsterdam

- 2001: TGV Mediterranean between Lyon and Marseille and Montpellier

- 2007: TGV East, to Strasbourg.

To capture the long-term effects, we decided to include only the TGV network that had opened by December 2007. For this reason, we have excluded the TGV East, which was commissioned in 2011. But, we decided to include the TGV Mediterranean, although 2007 is close to 2001, because the Mediterranean regions have gradually benefited from speed increases, as shown in Table 1.

Table 1. Travel time between Paris and Marseille.

\begin{tabular}{|c|c|c|c|c|c|c|}
\hline Year & 1954 & 1962 & 1969 & 1981 & 1994 & 2001 \\
\hline Travel time & $8 \mathrm{~h} 03$ & $7 \mathrm{~h} 10$ & $6 \mathrm{~h} 40$ & $5 \mathrm{~h} 30$ & $4 \mathrm{~h} 14$ & $3 \mathrm{~h} 00$ \\
\hline
\end{tabular}

Source: Leboeuf, 2014.
These accessibility gains were not limited to very large urban areas. For technical reasons, HSTs can only be operated at high speed on specially designed tracks, but at ordinary speeds, they can also use "conventional" tracks. Thus, the trains are able to serve a significant number of medium or small cities. It follows that the accessibility gains can be spread over a large area.

We can exemplify this spread of accessibility gains by looking at the Brittany region. Brittany is both a peripheral region and also one of the poorest in France (with a GDP per capita 20\% lower than the average for France), and yet, thanks to its classic railway connection with the TGV network, most of the region's inhabitants have much improved accessibility to Paris (Fig. 2). Moreover, feedering coaches connect small towns to HSR stations enabling the inhabitants to travel conveniently to Paris.

To measure the regional effects, we grouped the French regions into three categories:

- The regions without TGV (which will be referred to as 'Reference' regions);

- The regions with TGV that are adjacent to Paris (which will be referred to as 'TGV adj.');

- The regions with TGV that are not adjacent to Paris (which will be referred to as 'TGV').

- The Paris region (Ile-de-France) was excluded from the sample of regions.

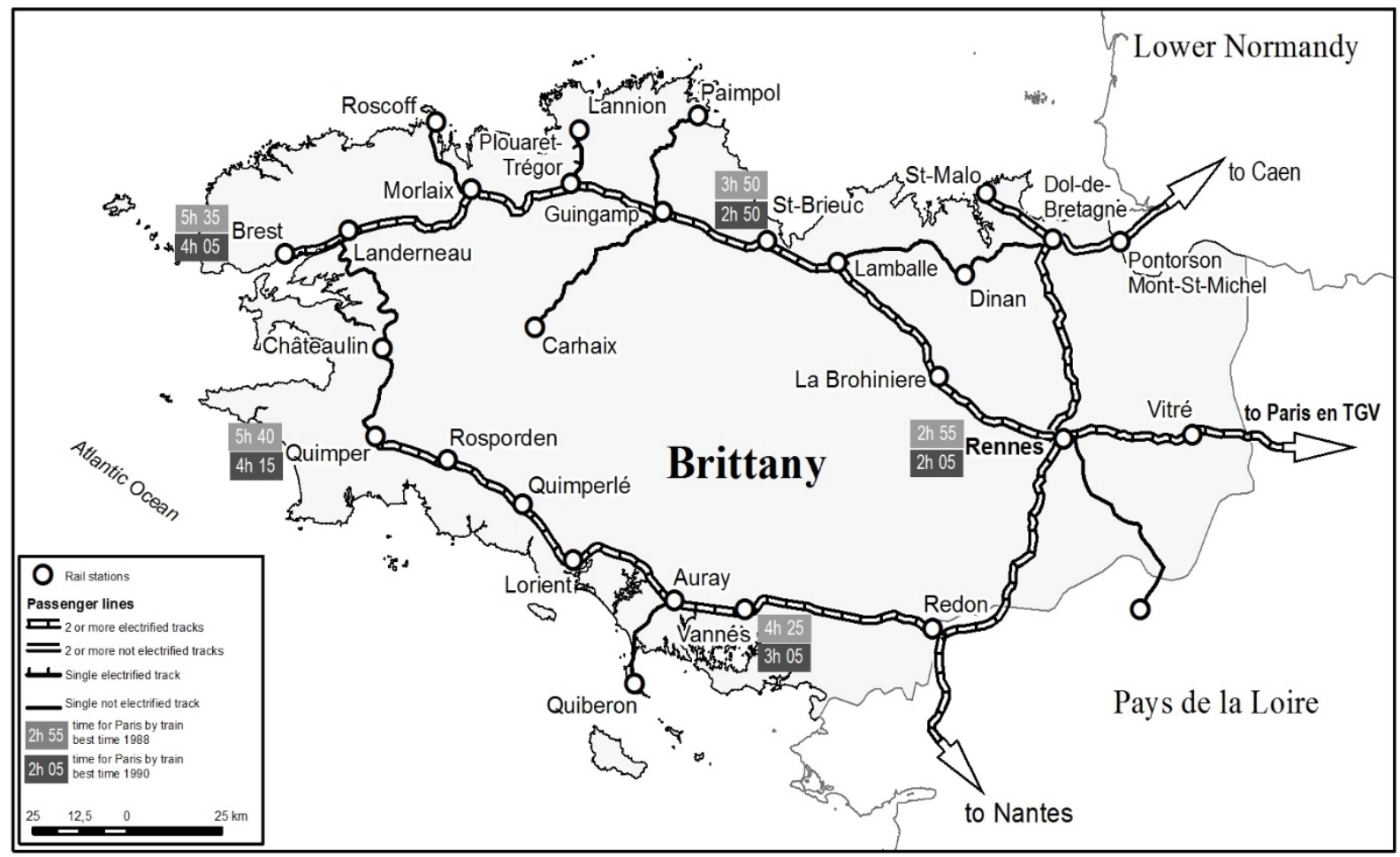

Source: Adapted by I. Baraklianos from RFF.

Figure 2. The spread of the benefit of high speed rail in a peripheral region: the case of Brittany 
We have decided to analyse the regions adjacent to Paris separately for several reasons. First, the relative gain in accessibility is smaller than for the other regions. Secondly, there is probably more trans-regional commuting to and from Paris and we would like to avoid this complex issue (see Andersson et al. 2009 for the Taiwanese case, Vickerman 1997, Vickerman 2015 for Europe and France). Thirdly, the HSLs serve only part of the region, and for some cities, the existing rail services to Paris have been downgraded or even stopped. Finally, as these regions are close to Paris, for some cities the car could be the preferred mode for journeys to Paris. A list of the French regions with their status according to their TGV services is presented in the following map (Fig. 3).

First, the GDP per capita will be examined between 1990 and 2007 (the opening of the TGV East). Even if the literature is inconclusive (Barro R. J. and Sala I Martin X., 1991; Dall'Erba S. and J. Le Gallo, 2005), it is necessary to control for $\beta$ convergence (the tendency of the poorest regions to have a higher rate of growth). The equation for the estimated model is as follows:

$\mathrm{GDP}_{\mathrm{i}}=\mathrm{a} \cdot \mathrm{D}_{1}+\mathrm{b} \cdot \mathrm{D}_{2}+\beta \ln \left(\mathrm{GDP}_{\mathrm{i} 0}\right)$, where:

- $\quad \mathrm{i}$ denotes the region

- $\mathrm{GDP}_{\mathrm{i}}$ is the increase in the GDP per capita in region $\mathrm{i}$ divided by the growth in the national GDP during the period

- GDPi0 is the initial per capita GDP of region i

- $\mathrm{D} 1$ is a dummy equal to 1 if the region has the TGV, and zero otherwise

- $\quad \mathrm{D} 2$ is a dummy equal to 1 if the region is a TGV adj. region, and zero otherwise.
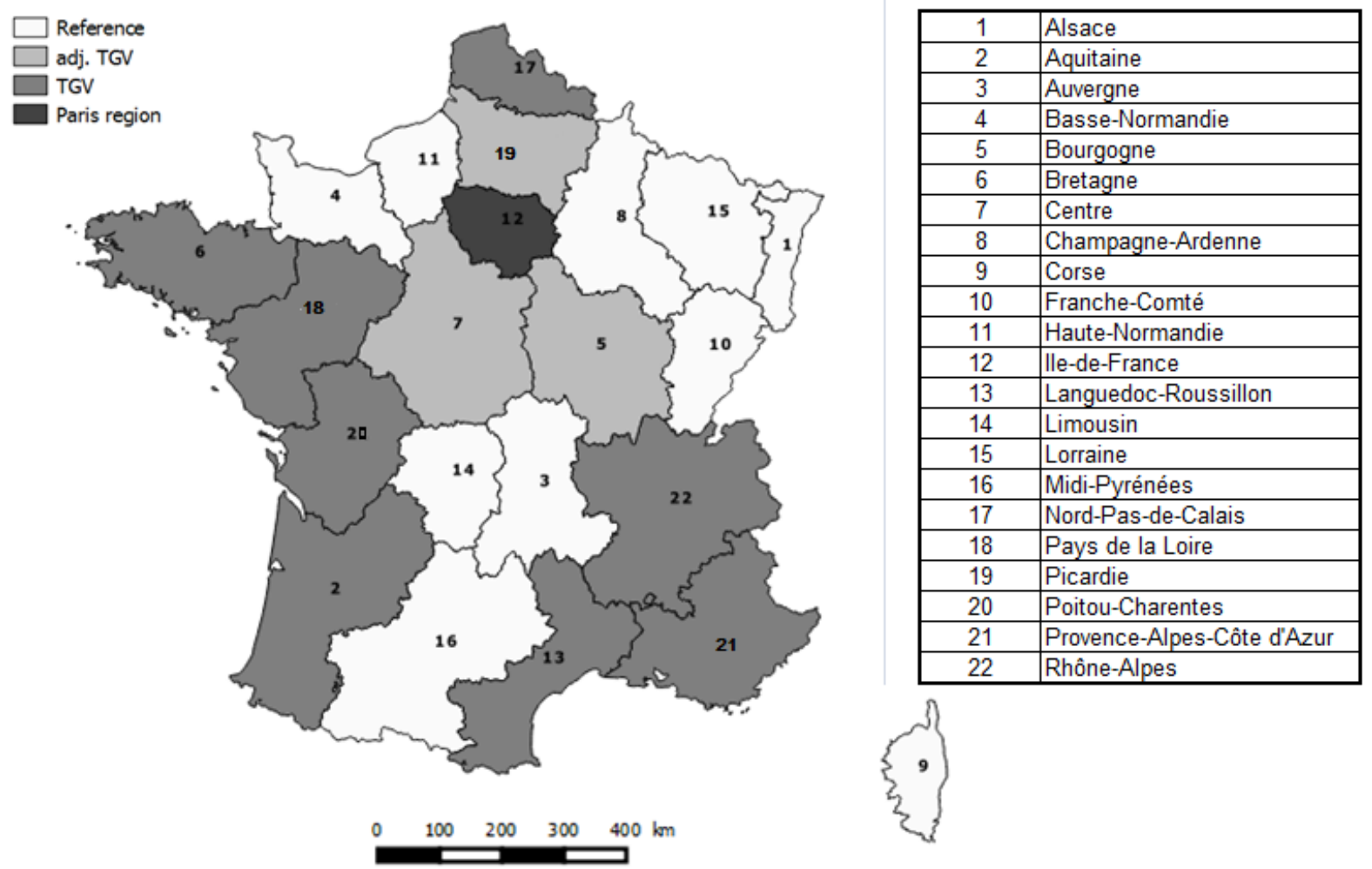

Source: The authors, from INSEE, 2007.

Figure 3. Regions according to TGV (HST) services provided 


\subsection{The Results of the Model}

The results of the regression are presented in Table 2.

Table 2. Regression of the relative growth of the regions served by TGV

\begin{tabular}{|c|c|c|}
\hline Coefficient & Value & P value \\
\hline a. & 0.06 & 0.02 \\
\hline b. & -0.066 & 0.08 \\
\hline$\beta$ & -0.13 & 0.15 \\
\hline
\end{tabular}

The growth in per capita GDP in the regions with TGV is significantly higher than that of those without (Reference), by around $6 \%$. The per capita GDP of the TGV adj. regions grew less (by 6.6\%) than that of the reference regions. Our hypothesis has been confirmed. This result is not very marked because of the small number of regions with the TGV adjacent to Paris. The difference between regions with $\mathrm{TGV}$ and $\mathrm{TGV}$ adj. regions is considerable: $12.6 \%$ over 17 years. The hypothesis of $\beta$ convergence is not supported by the data. But we should nevertheless bear the convergence hypothesis in mind, in order to control for this tendency. Some other specifications of the model have shown a significantly negative $\beta$ value.

We also estimated a control model, which involved the creation of a new dummy variable, grouping together the five regions that are adjacent to Paris. The results were the same, but the coefficient was not significant at the $10 \%$ level. This means we cannot be sure that there is a tendency for the regions which share a border with the Paris region to have a lower growth rate in terms of GDP per capita. Taken together, the five regions adjacent to Paris do not exhibit slower growth in their per capita GDP. This is thus limited to the TGV adj. regions. This effect has already been observed and analysed (Vickerman, 2015).

The results for demographic growth are presented in Table 3 .

Table 3. Regional demographic growth in France.

\begin{tabular}{|c|c|}
\hline Group of regions & Growth 1990-2007 (\%) \\
\hline France (metropolitan) & 12.5 \\
\hline Paris (IDF) & 12.5 \\
\hline Regions with TGV & 16.3 \\
\hline $\begin{array}{c}\text { Regions without TGV } \\
\text { ("Reference” in Fig. 3) }\end{array}$ & 8,4 \\
\hline $\begin{array}{c}\text { TGV adjacent } \\
\text { (“Adj. TGV” in Fig. 3) }\end{array}$ & 6.1 \\
\hline Champagne-Ardenne & -0.1 \\
\hline Haute-Normandie & 6.4 \\
\hline
\end{tabular}

We have added two regions that are adjacent to the Paris region with no TGV (Champagne and Haute-Normandie to the three previously identified categories of regions. From this table, we can infer the following:

- Demographic growth is highest in the 'Regions with TGV';
- Demographic growth is lowest in 'TGV adj.' regions as well as in adjacent regions which do not have the TGV.

Changes in GDP are a combination of changes in the population and per capita GDP. Our results are summarised in Table 4.

Table 4. GDP growth per group of regions.

\begin{tabular}{|c|c|}
\hline Group of regions & Growth 1990-2007 (\%) \\
\hline France (metropolitan) & 38.3 \\
\hline Paris (IDF) & 39.5 \\
\hline Regions with TGV & 43 \\
\hline $\begin{array}{c}\text { Regions without TGV } \\
\text { ("Reference” in Fig. 3) }\end{array}$ & 32 \\
\hline $\begin{array}{c}\text { TGV adjacent } \\
\text { (“Adj. TGV” in fig. 3) }\end{array}$ & 28 \\
\hline Champagne-Ardenne & 27.5 \\
\hline Haute-Normandie & 33.6 \\
\hline
\end{tabular}

The data summarised in Table 4 are compatible with a concentration of growth in the regions with a TGV. The GDP in these regions grew by eleven points more than in the regions without a TGV (not adjacent). The regions with TGV grew more than $3.5 \%$ than Paris (as a percentage of the base year figure).

This leads to a general conclusion on the effects of accessibility gains (mainly to Paris) for the regions served. The data are consistent with a polarisation effect which favours the concentration of economic and demographic growth in some regions. The regions without high speed rail are somewhat "left out". The regions adjacent to Paris are even more so. This is consistent with previous observations and analyses, notably those of Vickerman (1997, 2015)

It is interesting to note that the GDP of Paris grew more than that of France as a whole but less than that of the regions with TGV. This does not support the fears, expressed in the $80 \mathrm{~s}$, that Paris would benefit the most from the HSLs. On the contrary, the data are consistent with a process of "spreading": Paris is the major node of the knowledge-based economy, and the regions with TGV are benefiting from its driving power.

\subsection{The Issue of Equity with Respect to Accessibility Gains}

The improved accessibility provided by HST creates some privileges. By its very nature, an HST is not a fair investment. We shall now look in greater detail at the HST accessibility effect with regard to the previously defined concepts of equity.

The concept of procedural fairness does not apply to this accessibility gain. While investments in HSL are systematically subjected to a socio-economic evaluation, both to assess their usefulness (appropriateness) and degree 
of urgency (priority), in practice the final decision is a matter of policy. The rules of economic calculation are often set aside in favour of political considerations influenced by a complex set of local and regional actors.

Equity as the fulfilment of expectation does apply. If we consider what we have called the "TGV adj. regions", one could have expected that being served, at least partly, by the TGV would have a beneficial effect on their GDP or population growth. This is not the case. So we can consider that their expectations have not been met. On the contrary, it seems that the (non-adjacent) regions with the TGV have benefited from the HSLs. In a certain way, this is consistent with the expectation of the majority of people living in them. But we have to be cautious: HSLs might have given rise to a new way of life or urban pattern that not everybody would have expected. In particular, new HSLs may have favoured a trend towards gentrification and some low-income renters may have been forced out of the area near the station. Moreover, individuals who do not use HSTs suffer side-effects (increases in land prices, more noise near the HSL or the stations, more congestion on the transit lines during the peak hours of HST departure...) without experiencing any benefits.

The concept of formal equality leads us to see investment in the TGV as unfair: some comparable citizens living in two different areas face different prospects, depending on whether they are served by HSTs or not. The mere fact of being located in an important node on a busy corridor confers the right to enjoy the benefits of an HSL. The inhabitants of the chosen locations benefit from a number of advantages if we trust the hypothesis, consistent with the data, that HSL brings wealth and demographic growth. An increase in rents might appear to be windfall for some inhabitants, but detrimental for others (but we should not ignore the complexity of this question). This issue is not specific to HSLs. To a certain extent, it is true for any transport improvement, but in the case of HSLs, the effects could be region-wide.

For the same reason, HST might be considered unfair according to the substantive equality concept or the equality of choices. Indeed, some "conventional" trains have been withdrawn, adversely affecting some small cities. The balance of net advantages has deteriorated for people in these cities and their choice sets have been reduced by the TGV.

Regarding meritocracy, the high speed lines were chosen according to the potential traffic or as a result of political soft power, which is not linked in any way to merit. According to the consensus, a strong commitment to regional development is required in order to benefit from the economic and demographic impact of HSR. This can be seen as a form of "meritocracy".
Looking beyond the concepts of equity proposed by Hay, several observations are useful. In the French context, better accessibility generally means better accessibility to Paris. But this is not the only outcome. For example, the primary benefit from the TGV between Lyon and Marseille has been to favour travel between Paris and Marseille. But the new line provided more possibilities for improving some local and regional connections. Furthermore, there is a systemic effect associated with any $\mathrm{HSL}^{2}$ and we have to recognise that our macroeconomic representation does not fully capture this. However, this fact does not substantially reduce the unfairness of HST, rather the contrary.

The geographical polarisation at national level caused by the TGV, and a number of other factors, has already been reported (Monzon and al., 2013, Vickerman, 1997). This is not an equitable process as Martinez Sanchez-Mateos and Givoni (2012) expected. However, if the spreading hypothesis is confirmed, the HSLs may help to improve balance at the national level by reducing the dominance of the capital. To a certain degree, this improved accessibility might have caused both polarisation and spreading toward some favoured regions. But very much depends on the funding of the infrastructure and the price paid for using the HSTs.

\section{Pricing and Funding Policy}

To obtain a comprehensive view of the impact of HST on spatial equity, we need to consider pricing and funding.

\subsection{Pricing Policy: Empirical Evidence}

We used the SNCF web site to compare some prices for different types of journeys. First, we compared the journey from Paris to Lyon, Nantes, Marseille, Montpellier and a smaller city not too far from Paris - Le Mans. Then we addressed the question of travelling between Lyon and some southern cities: Valence, Marseille, and Montpellier. Finally, we looked at the journey from Lyon to Lille (in the North) and Nantes (in the West), both of which involve by-passing Paris.

The results are presented in Table 5. All the prices were for second class tickets without any reduction.

2 What we call systemic effects are the effects on a system which can be broader that the simple HSL. This may involve both supply and demand. For example, a classical line may benefit from generated traffic and with the benefit of economies of density the unit costs may decrease for this line. Regarding demand, a time saving on an O-D pair might benefit a city that is not located directly on the new infrastructure (an example is Paris/Grenoble which has benefited from the time savings on the Paris/Lyon journey). Note added to the 2020 version. 
Table 5. Our sample of prices

\begin{tabular}{|c|c|c|c|c|c|c|c|}
\hline \multirow{2}{*}{ From } & \multirow{2}{*}{ To } & \multirow{2}{*}{$\begin{array}{l}\text { 1-month } \\
\text { discount }\end{array}$} & \multirow{2}{*}{$\begin{array}{l}\text { 4-month } \\
\text { discount }\end{array}$} & \multirow{2}{*}{$\begin{array}{c}\text { Length } \\
\text { (road) }\end{array}$} & Cents per km & Cents per km & Ratio \\
\hline & & & & & (1 m disc.) & (4 m.disc.) & $1 \mathrm{~m} / 4 \mathrm{~m}$ \\
\hline \multirow{7}{*}{ Paris } & Lyon & 92 & 30 & 466 & 19.7 & 6.4 & 3.1 \\
\hline & Le Mans & 31.6 & 20 & 212 & 14.9 & 9.4 & 1.6 \\
\hline & Strasbourg & 71 & 71 & 492 & 14.4 & 14.4 & 1.0 \\
\hline & Nantes & 47 & 20 & 381 & 12.3 & 5.2 & 2.4 \\
\hline & Lille & 26 & 15 & 221 & 11.8 & 6.8 & 1.7 \\
\hline & Montpellier & 71 & 37 & 750 & 9.5 & 4.9 & 1.9 \\
\hline & Marseille & 57 & 40 & 777 & 7.3 & 5.1 & 1.4 \\
\hline \multirow{5}{*}{ Lyon } & Nantes & 143.2 & 60 & 723 & 19.8 & 8,3 & 2.4 \\
\hline & Valence & 18 & 14.3 & 104 & 17.3 & 13.8 & 1.3 \\
\hline & Lille & 111.5 & 45 & 692 & 16.1 & 6.5 & 2.5 \\
\hline & Marseille & 47.3 & 47.3 & 315 & 15.0 & 15.0 & 1.0 \\
\hline & Montpellier & 27 & 20 & 303 & 8.9 & 6.6 & 1.4 \\
\hline
\end{tabular}

Source: SNCF web site, visited on the $8^{\text {th }}$ of May 2013. All these prices are for trains whose departure was between 6:15 and 6:30 a.m. on Tuesdays. We calculated the distances on the "Mappy" web site. In this case we included the TGV East (Strasbourg).

We can report four main findings with regard to HST pricing.

a). For a given journey, tickets purchased four months in advance are almost always much cheaper than those bought one month in advance. In some cases, the difference is enormous, for example for Paris to Lyon the difference is 30 Euros versus 92 Euros. These differences can be observed for all destinations (see the last column in Table 5). On average, in our sample, the tickets bought one month in advance are $80 \%$ more expensive than ones for the same destination purchased four months in advance. In contrast, a few other links offer no discount for early purchase, e.g. Paris-Strasbourg and Lyon-Marseille.

b). The second observation is that SNCF's fare structure for the TGV is not cost-oriented. The average price per TGV-kilometre is highly variable, depending on the origin and destination and the date of purchase. For example, purchased one month in advance, the Paris-Marseille ticket $(777 \mathrm{~km})$ cost $€ 57$, less than the ticket from Paris to Lyon, which cost $€ 92$ for a distance of $446 \mathrm{~km}$. Paris-Lyon appears to be a "cash cow". We can ask ourselves whether the Paris-Marseille line is profitable. This results in a transfer of well-being between the Lyon region and the rest of France, particularly Marseille.

c). If we consider the price per $\mathrm{km}$, there is a huge difference between the highest $(€ 19.7)$ and the lowest $(€ 7.3)$. The highest price, from Paris, is about 2.7 that of the lowest. The fare structure of the HST seems to be oriented towards revenue maximisation which is probably due to the yield management approach adopted by SNCF (the train operator).

d). We can observe that some links are subjected to very high fares (Paris-Lyon and Paris- Strasbourg, for example). Is this monopoly pricing? On these links, there is no intermodal competition: the distances are too great for coaches and too small for airlines. In the parlance of business management, we can refer to these as "cash cows".

\subsubsection{How can We Explain These Pricing Results?}

In contrast to other domestic passenger fares, today's TGV pricing operates on the principles of yield management. SNCF was the first railway company in the world to implement this approach. Taken from the airlines (American Airlines in the case of the software used by the SNCF), yield management is based on occupancy across time (Smith and al., 1992). Thus, when the departure date draws closer, the price increases. The same principle applies to occupancy rates. However, there are some rules. a). The prices paid by users are set on the basis of regulated fares corresponding to the reference price of second-class journeys;

b). Fare modulation is left at the discretion of the railway company, but must not exceed plus or minus $40 \%$ of the reference price;

c). SNCF must provide a number of discounted tickets to customers that correspond to a percentage of total annual ticket sales.

The issue of the reference price is crucial. In practice, there is not a single price ceiling for all TGVs, but as many prices as routes. For HSR, the key factor that determines SNCF's pricing is clearly the potential for intermodal competition (airlines, coaches in the future). Thus, competition from the airlines explains why some prices are lower (the price for Paris-Marseille is much lower than for Paris-Lyon).

Overall, SNCF's HSR fares are subject to various constraints. The most obvious of these are intermodal 
competition and the sector's huge fixed costs (because of the cost of replacing rolling stock). In Europe, operators are separate entities from the infrastructure managers and are required to pay infrastructure charges. These charges affect the fares.

\subsubsection{The Issue of Equity}

Regarding "procedural justice", HSR clients are confronted by the fact that there are no apparent rules, apart from those deriving from the will to maximise revenue. TGV fares are routinely criticised for their lack of transparency by passengers and user groups (FNAUT, 2011). We can, therefore, consider that the pricing rules are not applied uniformly over space.

As regards "legitimate expectations", customers can expect that booking a ticket four months in advance will entitle them to a substantial discount. This is usually the case but is not true for every link. A customer would also expect to pay less for a shorter distance. However, this is not always the case either, as witnessed by the Paris-Lyon-Marseille link. Passengers pay more to travel from Paris to Lyon than from Paris to Marseille. In addition, to travel from Paris to Marseille, travellers need to go first to Lyon $(450 \mathrm{~km})$ before continuing to Marseille (about $300 \mathrm{~km}$ ). The travellers in question, who are the victims of monopoly pricing, can, to a certain extent, consider that their expectations have not been met.

"Formal equity" is seriously breached. Depending on passengers departure point and destination, they have to pay very different prices (in terms of cents per $\mathrm{km}$ ) even for comparable distances. For example, from Paris to Montpellier, the price is $€ 71$ (9.5c. per km) while Paris to Marseille costs $€ 57$ (7.3c. per km).

As far as "substantive equality" is concerned, we have to take a moderate view. To a certain extent, the customer who is willing to pay a given price for a journey should assess its costs and benefits. But, sometimes the customer has no choice, and either they or their firm has to pay, because there is either no alternative transport mode or it is too expensive. The introduction of the TGV network has been partly at the expense of the conventional rail network. Usually, nowadays, the timetables are less attractive for the travellers departing from these "small" stations, compared with the situation that existed prior to HSR.

It is also obvious that "equality of choices" is seriously breached. For a Parisian with a limited amount of money to spend, it is better to go to Marseille than Lyon or Strasbourg. And conversely, to go to Paris, it is better to live in Marseille, than Lyon or Strasbourg. If you are a businessman from Lyon, you might prefer to go to a meeting in Montpellier rather than Marseille. Browsing the website of the rail operator (SNCF) provides some astonishing examples of the absurd consequences of a hub and spokes network. For example, Bordeaux and Rennes, cities in western France, are both are linked to Paris by HST. Travelling by train involves passing through Paris.

If we return to the topic of "consistency with merit", the fare structure appears to breach the very concept of equity. If the fare structure was cost-related, we could admit that there is a degree of justice. But this is not the case. And thus, having the merit to be in competition with a low-cost carrier (e.g. Paris-Marseille) does not allow one to benefit from discounted fares. Having or not having an affordable alternative to HST is not a merit per se. As far as "rights" are concerned, there is, in France a so-called "right to transportation" (LOTI, 2002). Among the constraints imposed by the State on the national railway company (SNCF) are that it has to offer its customers a minimum number of tickets below a reference price.

\subsubsection{Comparison with Other European Countries: do "Cash Cow" HS Trains Exist Elsewhere?}

We shall briefly address the question of equitable pricing on three other European railways with high speed services: Germany, the UK (if we apply the UIC definition, the UK has more than one HSL) and Spain (the longest HSR network in Europe).

What we are looking for are "cash cows" and "price reversal", applying the same methodology we did for France. 
Table 6. Prices examples of HSR destinations in other European countries

\begin{tabular}{|c|c|c|c|c|c|c|c|}
\hline & & $\begin{array}{c}\text { Price with } 1 \\
\text { month discount. }\end{array}$ & $\begin{array}{c}\text { Price with } 2 \\
\text { months discount }\end{array}$ & $\begin{array}{l}\text { Distance (road, } \\
\text { km) }\end{array}$ & $\begin{array}{l}\text { Cents per road } \\
\mathrm{km} 1 \text { month }\end{array}$ & $\begin{array}{l}\text { Cents per road } \\
\mathrm{km} 2 \text { months }\end{array}$ & $\begin{array}{l}\text { Ratio between } \\
\text { discounts for } 1 \\
\text { and } 2 \text { months. }\end{array}$ \\
\hline \multicolumn{8}{|l|}{ Spain } \\
\hline \multirow[t]{5}{*}{ Madrid } & Ciudad Real & 37.2 & 36.4 & 204 & 18.24 & 17.84 & 1.02 \\
\hline & Zaragoza & 54.6 & 54.6 & 314 & 17.39 & 17.39 & 1 \\
\hline & Cordoba & 62.1 & 62.1 & 387 & 16.05 & 16.05 & 1 \\
\hline & Seville & 75.5 & 75.5 & 529 & 14.27 & 14.27 & 1 \\
\hline & Barcelona & 106.7 & 106.7 & 617 & 17.29 & 17.29 & 1 \\
\hline \multicolumn{8}{|l|}{ Germany } \\
\hline \multirow[t]{3}{*}{ Frankfurt } & Köln & 69 & 69 & 192 & 35.94 & 35.94 & 1 \\
\hline & Stuttgart & 61 & 61 & 206 & 29.61 & 29.61 & 1 \\
\hline & Munchen & 98 & 98 & 420 & 23.33 & 23.33 & 1 \\
\hline Berlin & Leipzig & 46 & 46 & 196 & 23.47 & 23.47 & 1 \\
\hline Hanover & Munchen & 129 & 129 & 631 & 20.44 & 20.44 & 1 \\
\hline UK & & Pounds & Pounds & $\mathrm{km}$ & Euros c. & Euro c. & \\
\hline \multirow[t]{5}{*}{ London } & Birmingham & 14 & 14 & 190 & 8.69 & 8.69 & 1 \\
\hline & Manchester & 108.5 & 34 & 322 & 39.76 & 12.46 & 3.19 \\
\hline & York & 30.5 & 30.5 & 330 & 10.91 & 10.91 & 1 \\
\hline & Newcastle & 28.5 & 38 & 446 & 7.54 & 10.05 & 0.75 \\
\hline & Glasgow & 54 & 50 & 650 & 9.8 & 9.08 & 1.08 \\
\hline
\end{tabular}

Source: National rail inquiries, RENFE web site, Bahn.com, visited on the 13rd of May 2013.

The first observation is that, unlike in France, there is no clear and convincing evidence of yield management in the other European countries. The price usually remains stable over time for all the rail links in our sample, with almost no discount price for purchase in advance (Table 6, last column).

Our second observation is that cash cows are not confined to the French HST. This is surprising to find this practice in both the UK, the epitome of free-market entrepreneurship, and in France, the epitome of state-owned monopolies. London-Manchester is a perfect example of a cash cow. When a ticket is purchased one month before departure, the price in cents per kilometre is $€ 39.8$ compared with only $€ 9.8$ for Glasgow, the total price for Glasgow being less than half the price for Manchester.

So generally speaking HST pricing systems do not seem to be governed by equity. However, in connection with ongoing changes in European railway regulation (the fourth railway package), we can ask ourselves if the introduction of competition may lead to a more equitable pricing system. It is possible for competition on the track to decrease prices on the more highly-priced segments (notably Paris-Lyon and Paris-Strasbourg). But such competition raises a great many questions (Pérennes,
2014)

\subsubsection{Is Ouigo a New Concept of HST from the} Standpoint of Pricing Equity?

However, for the sake of completeness on the issue of pricing, we must also include the impact of Ouigo low-price high-speed rail services in our analysis. Ouigo is SNCF's recently launched low-cost company (dating from April 2, 2013). The aim is to attract new customers who previously travelled by car because previous rail services were not competitive with the car (Ciry, 2014).

This new product is only available on very busy links, Marne-La-Vallée-Chessy (a suburb of Paris, linked to the centre by suburban rail) to Marseille and Montpellier. There are three return services a day and four on Sundays (44 journeys a week). In order not to compete with the TGV, Marne-La-Vallée-Chessy was chosen as the station in the Paris region. In Lyon, the chosen station was Saint-Exupery, the station at the city's airport which is connected with the city centre by LRT. The two stations in the centre of Lyon, Perrache and Part-Dieu, are served by Ouigo, but as its terminus; connection with the southern Ouigo network is nevertheless possible, but by regional train (Fig. 4). 


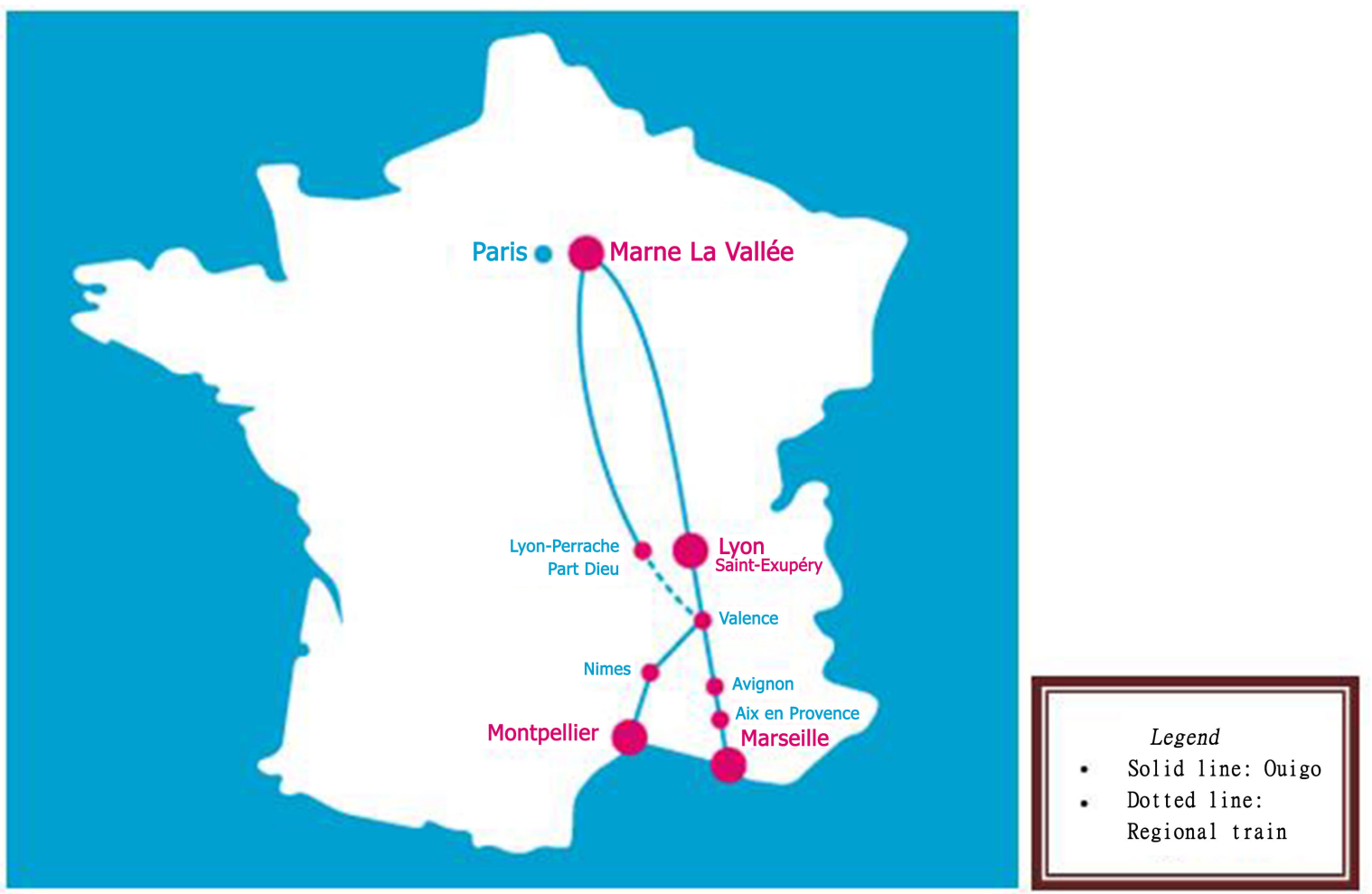

Source: http://www.ouigo.com/fr/destinations-et-gares - Visited on the 2 of March 2015.

Figure 4. Map of TGV Ouigo network.

Table 7. Examples of access to Ouigo stations by public transport from the city centre.

\begin{tabular}{|c|c|c|c|c|c|}
\hline Ouigo Stations & $\begin{array}{c}\text { Marne-la-Vallée } \\
\text { Chessy }\end{array}$ & $\begin{array}{c}\text { Lyon -Saint-Exupéry } \\
\text { Airport }\end{array}$ & $\begin{array}{c}\text { Aix en Provence } \\
\text { TGV }\end{array}$ & Valence TGV & Avignon TGV \\
\hline $\begin{array}{c}\text { Access time to the } \\
\text { city centre }\end{array}$ & $50^{\prime}$ (RER A) & $\begin{array}{c}30 \text { ' (suburban rail, } \\
\text { 'Rhône Express') }\end{array}$ & $\begin{array}{c}20 \text { ' (county Bus) } \\
\text { Frequency }\end{array}$ & $\begin{array}{c}20 \text { ' (Express Bus, } \\
\text { 'Inter Citéa') }\end{array}$ & $\begin{array}{c}\text { Suburban rail: 5' } \\
4,5 \text { Km by car: } \\
9\end{array}$ \\
\hline $\begin{array}{c}\text { One-way ticket price } \\
\text { (excluding any } \\
\text { discount) }\end{array}$ & $7.6 €$ & 15 ' & 14 ' & $\begin{array}{c}15 \text { ' (rush hour) } \\
\text {-60'(off-peak hour) }\end{array}$ & 60 ' \\
(round-trip ticket) & $4.1 €$ & $1.2 €$ & $1.6 €$ \\
\hline
\end{tabular}

Source: From various public transport websites - Visited on the $2^{\text {nd }}$ of March 2015.

The prices are really attractive, with second-class fares (the only class available) ranging from $€ 10$ to $€ 85$. If accompanied by an adult, children under 12 years old only pay a $€ 5$ flat fare. Moreover, under the terms of its contract with the State, SNCF must provide 1 million tickets a year at under $€ 25$ (irrespective of the distance). In addition to the low prices, tickets can only be booked on line and services are limited, with passengers restricted to just one free piece of luggage, no bar on board, and a check-in before boarding the train at least 30 minutes before departure. Moreover, the tickets are personal, only exchangeable with financial penalties, and only refundable if the train is cancelled. Booking is only possible a maximum of 10 weeks before departure. Finally, a major constraint is that half of the 10 stations served by Ouigo are outside the city frequently entailing long access times to central areas (in particular at Marne-La-Vallée-Chessy and Lyon Saint-Exupéry), or, in some cases a significant financial cost (Table 7).
To have a clearer idea of Ouigo's fare structure, we analysed the prices on some of the main services (Table 8). We obtained five main findings:

a). Tickets purchased in advance are almost always less expensive than those bought shortly before departure for the same destination, with a ratio varying from 1.5 to 2.5 .

b). Ouigo's fares are not cost-oriented as witnessed by the similar price of the ticket from Marne La Vallée Marseille and Marne La Vallée - Lyon for the same departure time.

c). Potential demand has a great impact on the price level. This is why tickets for journeys during the school holidays are more expensive (for example Tuesday 21 October).

d). Such prices are real: three weeks before departure, it is possible to find tickets for all the destinations proposed for 10 or $15 €$, much cheaper than all the alternative means of transport. 
Table 8. Sample prices for some TGV links on Ouigo

\begin{tabular}{|c|c|c|c|c|c|c|}
\hline In euros & $\begin{array}{c}\text { Tuesday } 14 \\
\text { October }\end{array}$ & $\begin{array}{c}\text { Tuesday } 14 \\
\text { October }\end{array}$ & $\begin{array}{c}\text { Tuesday } 21 \\
\text { October }\end{array}$ & $\begin{array}{c}\text { Tuesday } 21 \\
\text { October }\end{array}$ & $\begin{array}{l}\text { Tuesday } 4 \\
\text { November }\end{array}$ & $\begin{array}{l}\text { Tuesday } 4 \\
\text { November }\end{array}$ \\
\hline Marne-La Vallée - Lyon & $12: 22: 25 €$ & 19:26: $30 €$ & $12: 22: 45 €$ & 19:26: $45 €$ & 12:22: $10 €$ & 19:26: $10 €$ \\
\hline Marne-La Vallée - Marseille & $12: 22: 25 €$ & 19:26: $30 €$ & $12: 22: 45 €$ & 19:26: $45 €$ & $12: 22: 10 €$ & 19:26: $10 €$ \\
\hline $\begin{array}{l}\text { Marne-La Vallée - } \\
\text { Montpellier }\end{array}$ & 11:00: $25 €$ & & 11:00: $50 €$ & & 11:00: $10 €$ & \\
\hline Lyon - Marne La-Vallée & 08:35: $20 €$ & $17: 13: 45 €$ & $08: 35: 40 €$ & $17: 13: 50 €$ & $08: 35: 10 €$ & $17: 13: 15 €$ \\
\hline Marseille-Marne-La Vallée & $08: 25: 15 €$ & 16:28: $10 €$ & $08: 25: 45 €$ & $16: 28: 30 €$ & $08: 25: 10 €$ & 16:28: $10 €$ \\
\hline $\begin{array}{c}\text { Montpellier - Marne-La } \\
\text { Vallée }\end{array}$ & & $15: 24: 45 €$ & & $15: 24: 55 €$ & & 15:24: $15 €$ \\
\hline
\end{tabular}

Source: http://www.ouigo.com/fr - Visited on the $10^{\text {th }}$ of October 2014.

To obtain these 'low fares', SNCF had to drastically reduce its operating costs, by $30 \%$. It achieved this by introducing a mix of managerial and technical innovations. The choice of departure stations allowed SNCF to save on infrastructure charges, each of the four double-decker TGV Duplex offers a total capacity of 1,268 seats, almost $25 \%$ more than a standard TGV. In addition, this rolling stock will run much more than the other TGV, with many fewer stops for maintenance. The trains in question are also intended to be subjected to more intensive use than other TGVs. On-train staff costs have been reduced by organisational measures and most of the maintenance is done directly during the trip.

Ultimately, it would seem that Ouigo's fares have a considerable and generally positive impact on fairness. Firstly, because its fares are competitive - singularly so for families, young people and small groups - Ouigo provides significantly better value for money, which relates to our concept of "substantive equality". Ouigo is sometimes even cheaper than carpooling. Secondly, Ouigo has benefits with regard to the right to transportation, by providing some affordable journeys. SNCF claims than, during the first year, Ouigo had already carried over 2.5 million passengers.

After less than two years of operation, it is too early to make a full assessment of this new form of HST pricing and the necessary studies have not yet been carried out. Furthermore, SNCF plans to extend the Ouigo network with the opening of new lines to the Atlantic coast before 2017.

\section{2. Funding Policy: Empirical Evidence}

The last aspect of our study concerned the funding of the HSR network in France from the spatial equity point of view.

\subsubsection{French Funding of HSR}

With French funding of HST, we can make two main observations. The first is that each new project for an HSL involves a huge increase in cost, and the second is that the parties funding the projects are no longer the same
(Leboeuf, 2014).

To give some approximate figures, in 2003 constant value Euros the first HSL, which ran between Paris and Lyon cost $€ 4.8$ million per kilometer compared to $€ 9.3$ for the TGV Atlantic and $€ 9.5$ for the TGV North-Europe. More recently, the costs of the TGV Mediterranean amounted to $€ 17.5$ million per kilometer and those of the new SEA line (South-Europe-Atlantic amounted to $€ 16.2$ per kilometer. The second observation relates to changes in taxpayer subsidies. Since its inception, the funding of HSLs has become increasingly diverse, gradually bringing in local government. Our analysis reveals this to have been a four-stage process.

In the first period of investment in HSR, the investments were entirely provided by the SNCF budget, mainly from its own cash flow. The operator based its calculations on the hope that the high profitability of these lines would improve the financial health of the company.

In the second period, as a result of the deterioration of the financial position of SNCF, the national railway operator asked, successfully, for a proportion of the funding to be provided by central government $(30 \%$ in the LN2, TGV Atlantic).

For the third period, since the creation of RFF (1997), the independent infrastructure manager, funding consists of a mix involving a large subsidy from the State or the European Union, coupled with contributions from RFF and local authorities. This new scheme can be clearly observed in the financing of the LN6 (East TGV, first stage) and LN7 (Rhine-Rhône TGV).

The last stage, which is currently taking place, involves new funding mechanisms, with concession financing for Perpignan-Figueras or with a public-private partnership mechanism (PPP) for the SEA line (South-Europe-Atlantic) with Vinci, one of the main French construction companies.

For the last 4 on-going HSL construction projects, on average, public funds accounted for $55 \%$ of the funding, RFF barely $20 \%$, and private operators $25 \%$. Of the $55 \%$ of public funds, $1 \%$ is from the EU, $25 \%$ from local government and $29 \%$ from central government (Table 9, last column). 
Table 9. Funding of HSR in France

\begin{tabular}{|c|c|c|c|c|c|c|}
\hline & EAST $(1)$ & BPL $(1)$ & CNM (1) & SEA (1) & \multicolumn{2}{|c|}{ Total } \\
\hline & & & & & Amount & $\%$ \\
\hline Total cost $(€$ million) & 2000 & 3300 & 1800 & 7800 & 14900 & 100.0 \\
\hline Length $(\mathrm{km})$ & 106 & 182 & 80 & 303 & 671 & \\
\hline Cost/km $(€$ million) & 18.9 & 18.1 & 22.5 & 25.7 & 22.2 & \\
\hline Paid by RFF $(€$ million) & 520 & 1400 & - & 1000 & 2920 & 19.6 \\
\hline Paid by central government $(€$ million) & 680 & 950 & 1200 & 1500 & 4330 & 29.1 \\
\hline Paid by local government $(€$ million) & 640 & 950 & 600 & 1500 & 3690 & 24.8 \\
\hline Paid by EU + Luxembourg $(€$ million) & 160 & - & - & - & 160 & 1.1 \\
\hline
\end{tabular}

Source: RFF.

(1) EAST: second phase of the East European High Speed Line; BPL: Bretagne, Pays de la Loire; CNL: line Nimes-Montpellier bypass and SEA: South-East-Atlantic.

In short, the sources of funding have changed fairly quickly over the period in which the HSLs were built. SNCF withdrew from the investment market to give way to central and local government. RFF, the owner of the track is risk-averse and has no desire to be involved in risky investments.

\subsubsection{Funding and Equity}

Regarding "procedural justice", HST funding mechanisms differ depending on the line. This leads to spatial inequity. For the "three core lines" (South East, Western, Northern), local taxpayers were not called upon to pay. Conversely, with time, new investments have been on less-travelled links. Local government is asked to pay its share of the investment. This is the case, in particular, for the four HSLs that are currently planned or under construction in France (Table 9). Political bargaining probably outweighs the economic calculation. The rules are now flexible.

With regard to "legitimate expectations", the impact of a new high speed-line on a regional economy and the wider benefits are very difficult to estimate (see Part. 3). Local governments (and taxpayers) may find that their expectations are not met. Long term macroeconomic factors are very unpredictable and traffic modelling remains a very difficult art.

As regards "formal equity", we can observe a huge change: the conditions under which a decision to build a new HS line are becoming progressively stricter. Beneficiaries from the first HSLs (South-East, Atlantic, North) did not pay directly for the investment, while citizens affected by the most recent lines are asked to pay, through local taxes. For example, for the first stage of TGV East line, the local authorities had to pay about 740 million, or $24 \%$ of the total. The "Bas-Rhin" (a local district accounting for about half of the Alsace region) had to provide funding on a similar scale to Ile-de-France (the Paris region), whereas the population of the former is 1.2 million and that of the latter is 11.8 million.

With respect to "substantive equality", the different HST funders do not obtain similar net outcomes. The outcome depends on the specific HSL and the context (in terms of demand, macroeconomic factors, etc.). From the taxpayers' point of view, with state funding, we have already seen (Part. 3) that the economic and demographic benefits are located in different parts of the country. Everyone in the country participates in funding this infrastructure, but only some of them receive the benefits of HSTs. From the standpoint of local taxpayers, who are increasingly asked to participate in the funding, the balance is actually unclear. For example, there is no available data about whether the benefits received by local communities in Champagne-Ardennes, Alsace, or Lorraine were in proportion to their investment in the first stage of the HSL/East.

As far as "equality of choice" is concerned, the (spatial) distribution of choice sets is unequal for several reasons, essentially to do with the public finance context. Currently, there is not enough public money available to finance all the planned HST lines. Some projects have been halted in view of the unfavourable context (by the Commission Mobilité 21, for example). In addition, some HSL projects may be eligible, because of the priorities of the European Union, for TEN-T funds (East, first and second phase), others not (SEA). The European Union encourages international links between countries (Lyon-Turin, for example). Some areas or local governments have the financial capacity or political will to co-finance High Speed Rail, others not.

\section{Conclusions}

The first conclusion is methodological: Hay's definitions of Equity have been useful in order to address the impact of HSTs on spatial equity in France. However, we consider that further research is necessary to explore this question more fully. Some other definitions of equity regarding HST ought to be tested, given the complex fare grid in place for French Railways in 2020 (with a large Ouigo network in addition to InOui, the brandmark of the conventional $\mathrm{TGVs})^{3}$.

\footnotetext{
3 This point has been added to the conclusion of the 2020 version.
} 
The $19^{\text {th }}$ century was the time when the real high speed revolution in ground transportation took place (Whitelegg and al., 1993). This did not entail much inequity for two reasons. First, the rail networks achieved dense geographical coverage, meaning the benefits of high speed were widely distributed. Secondly, in an economy based upon industry, a certain degree of proximity was necessary between the productive activity and the service related to that activity. We are now in a knowledge-based economy facing globalisation and digitisation.

Our results are consistent with a polarisation effect. In a sense, HSTs are unfair because they are growth-inducing. As in the $19^{\text {th }}$ century, HSLs were developed where the growth potential was higher although a few regions benefited from a windfall. But with a few exceptions, the regions served by TGV are among the most dynamic in France. Surprisingly, although the TGV system converges in Paris, this central position does not appear to mean the Paris region benefits more than other regions from the TGV. We could call this tendency "spreading" as the knowledge-based economy, mainly based in Paris, is creating some benefits for more remote areas. So, the spatial impact of the TGV is mixed: polarisation, to the detriment of the regions not served, and the spreading of the benefits of the major driving force of the knowledge-based economy - Paris. However, our analysis is limited to France, and we should not forget that there is a genuine European network, at least in the North-West of Europe (Vickerman, 1997).

The financing of HSL in France has given rise to several types of spatial inequity for two major reasons. The first is the changing nature of the funders, which reflects a lack of procedural fairness. Whereas the first high-speed lines were fully supported by the national railway company, the most recent lines have been financed by a wide range of providers, with a significant contribution from local authorities. Private capital is also sometimes associated with public financing through PPPs. The second reason is the sharp increase in the per kilometre construction cost of lines, which significantly reduces the benefits to be expected from these new transport infrastructures. Moreover, there is no equality of net surpluses for each line, with the most recent lines proving to be much less profitable for the operator and the local actors than the first ones (Leboeuf, 2014). In the end, the actual impact of HSL on different parts of the country depends to a large extent on the policies implemented locally ${ }^{4}$.

The impact of HSR pricing on spatial equity is somewhat unclear. The adoption of the yield management railway pricing system leads to a peculiar and singularly unfair situation. The fare structure appears to be very little

4 This paragraph and the following have been added to the 2020 version. affected by costs, or even by distance. Links without effective intermodal competition (from air transport) result in monopoly prices ("cash cows"). Public regulation seems to have a secondary impact on HSR fares. As a result, HSR fares are not consistent with the various definitions of fairness proposed by Hay. Nevertheless, the deployment of low-cost HSR links, under the Ouigo brand, tends to provide really attractive prices and promote "substantive equality". And fortunately, other modes can mitigate this effect. While domestic air transport today does not seem to be a solution for the future, it remains to be seen whether car-sharing or long-distance coaches could also play a part in restoring equity.

The adoption of the yield management railway pricing system leads to a peculiar and singularly unfair situation. Fortunately, other modes can compete. Air transport seems to be more efficient than rail for intercity travel (Paris excluded). Moreover, air is not centralised at one major hub (so far in the case of LCCs). For intercity travel in France and Europe, air travel is more cost-effective and faster than rail. This provides a "second chance" for the regions with no HSL. It remains to be seen whether car sharing or coaches could play a part in restoring equity. The "green" argument in favour of railways seems to be becoming less convincing (Westina and Kagesona, 2012).

\section{REFERENCES}

[1] Albalate, D., Bel, G., 2012. High-Speed Rail: Lessons for Policy Makers from Experiences Abroad. Public Administration Review, May-June, 336-349.

[2] Andersson, D. E., Shyr, O. F., Lee, A. (2012). The successes and failures of a key transportation link: accessibility effects of Taiwan's high-speed rail, Annals of Regional Sciences 48, 203-223.

[3] Banister, D., Givoni, M., 2012. Speed: The less important element of the High-Speed Train, Journal of Transport Geography 22, 306-307.

[4] Barro, R.J., Sala I Martin, X., 1991. Convergence across states and regions. Brookings papers on economic activity. 91 (1), 107-182.

[5] Bonnafous, A., 1987. The regional impact of the TGV. Transportation, 14(2), 127-137.

[6] Chen, C.-L., Hall, P. 2012. The wider spatial-economic impacts of high-speed trains: a comparative case study of Manchester and Lille sub-regions. Journal of Transport Geography 24, 89-110.

[7] Ciry, B. 2014. Ouigo: un concept pionnier de la SNCF. Revue Générale des Chemins de Fer 234, janvier, 6-14.

[8] Dall'Erba, S., Le Gallo, J., 2005. Dynamique du processus de convergence régionale en Europe. Régions et Développement 21, 119-139. 
[9] FNAUT, 2011. Les arguments des opposants aux lignes à grande vitesse. Recensement, analyse et recommandations. Etude pour l'Association des villes et régions européennes de la grande vitesse.

[10] Garmendia, M., Ribalaygua, C., Ureñac, J.M., 2012. High speed rail: implication for cities. Cities 29, 526-531.

[11] Givoni, M, 2006. Development and Impact of the Modern High-speed Train: A Review. Transport Reviews 26(5), 593-611.

[12] Hay, A. M., 1995. Concepts of equity, fairness and justice in geographical studies. Transactions of the Institute of British Geographers, New Series, 20(4), 500-508.

[13] Leboeuf, M., 2014. Grande vitesse ferroviaire. Le Cherche Midi, Paris.

[14] Levinson, David M., 2012. Accessibility impacts of high-speed rail. Journal of Transport Geography 22, 288-291.

[15] LOTI, 2002. Loi $\mathrm{n}^{\circ} 82-1153$ du 30 décembre 1982 d'orientation des transports intérieurs. Journal Officiel du 31 décembre 1982.

[16] Martinez Sanchez-Mateos, H.S., Givoni, M., 2012. The accessibility impact of a new High-Speed Rail line in the UK - a preliminary analysis of winners and losers. Journal of Transport Geography 25, 105-114.

[17] Monzón, A., Ortega, E. Lopez, E., 2013. Efficiency and spatial equity impacts of high-speed rail extensions in urban areas. Cities 30, 18-30.

[18] Pérennes, P., 2014. Use of combinatorial auctions in the railway industry: Can the "invisible hand" draw the railway timetable?". Transportation Research Part A: Policy and Practice, 67, September, 175-187.
[19] Plassard, F., 1991. Le train à grande vitesse et le réseau des villes. Transports $345,14-23$.

[20] Preston, J., 2012. High Speed Rail in Britain: about time or a waste of time? Journal of Transport Geography 22, 308-311

[21] Rawls, J., 1971. A Theory of Justice. Harvard University Press, Cambridge, Massachusetts.

[22] Sands, B., 1993. The Development Effects of High-Speed Rail Stations and Implications for California. University of California Transportation Center, WP.

[23] Smith, B. C., Leimkuhler, J. F., Darrow, R. M., 1992. Yield Management at American Airlines, Interfaces 22(1), January-February, 8-31.

[24] UIC, 2011. High speed Rail as a tool for regional development. DB International $\mathrm{GmbH}$, Frankfurt.

[25] Urena, J.M., Menerault, P., Garmendia, M., 2009. The high-speed rail challenge for big intermediate cities: A national, regional and local perspective. Cities 26, 266-279.

[26] Vickerman, R., 1997. High-Speed Rail in Europe: Experience and Issues for Future Development. Annals of Regional Science 31(1): 21-38.

[27] Vickerman R., 2015. High speed rail and regional development: the case of intermediate stations. Journal of Transport Geography, 42, 157-165.

[28] Westina, J., Kagesona, B., 2012. Can high speed rail offset its embedded emissions? Transportation research part $D, 17$, $1-7$.

[29] Whitelegg, J., Hulten, S., Flink, T., 1993. Introduction in Whitelegg J. Hulten S., Flink T. (Eds) High speed trains: fast track to the future, Leading edge, London. 